\title{
Impacts of the overheating economy on China's manufacturing industry
}

\author{
Roy C. P. Chung $\cdot$ W. H. Ip • S. L. Chan
}

Received: 18 September 2008 / Accepted: 6 October 2008 / Published online: 4 November 2008

(C) The Author(s) 2008. This article is published with open access at Springerlink.com

\begin{abstract}
This paper aims to investigate how the recent overheating economy and other economic factors influence the manufacturing industry in China. It makes use of Chinese historical data from 1950 to 2007 provided in the China Statistical Databases authorized by the National Bureau of Statistics of China for the development of econometric models. Regression analysis is used to investigate and verify the importance of and relationships among the variables, while exponential smoothing and autoregressive integrated moving average methods are applied for forecasting the important variables. This study provides empirical evidence to identify the main impact factors on the growth of the manufacturing industry, thereby enabling firms to take them into account when planning their manufacturing strategy. It also enables firms to get an insight into the development of China's manufacturing industry in this dynamic, competitive economy.
\end{abstract}

Keywords China $\cdot$ Manufacturing industry .

Econometric models $\cdot$ ARIMA

R. C. P. Chung

Techtronic Industries Co. Ltd,

Hong Kong, SAR, China

e-mail: roy@tti.com.hk

W. H. Ip · S. L. Chan $(\bowtie)$

Department of Industrial and Systems Engineering,

The Hong Kong Polytechnic University,

Hong Kong, SAR, China

e-mail: sian.chan@polyu.edu.hk

W. H. Ip

e-mail: mfwhip@polyu.edu.hk

\section{Introduction}

Recently, there have been concerns and debates about China's overheating economy. In the first half of 2007, the gross domestic product (GDP) growth (11.5\%) and consumer price index (CPI, 6.5\%) in China even reached their highest point for a decade, while the Chinese currency has been appreciating strongly. These strongly suggest signs of overheating in China's economy. The evidence concerning the symptoms of this problem in China has been described as follows:

Robust economic growth: China's economy grew at an average rate of $10 \%$ per year since its economic reforms in 1978, representing the highest growth rate in the world. Recently, the economic growth of China has become vigorous. China's GDP grew by $10 \%$ in 2003 and even faster, by $10.1 \%$ in $2004,10.4 \%$ in 2005 , and $11.1 \%$ in 2006 [1], despite government attempts to cool the economy.

Exceptionally high inflation level: An uncontrollable rise in inflation in China is causing concern. In particular, the CPI rose by $3.9 \%$ in the period from January-August 2007, exceeding the 3\% target set by the central Bank for the year 2007. Worse, the inflation in August 2007 jumped to 6.5\%, up from 1.3\% in 2006 $[2,3]$, the highest rate for more than a decade. Although some argue that the high inflation rate is mainly due to the rise in food prices caused by supplyside problems [4], the exceptionally high rate still appears to be a symptom of the overheating economy in China. This is because it is difficult for China, with its over-rapid GDP growth, to lessen inflation through raising interest rates or the Chinese currency without leading to more general inflationary pressures. 
Fig. 1 Summary of literature on econometric models in China

\begin{tabular}{|c|c|c|}
\hline Authors & Major Findings & Determinants/Variables \\
\hline $\mathrm{Yu}[25]$ & $\begin{array}{l}\text { Used regression analysis to study } \\
\text { manufacturing growth } \\
\text { National income produced in } \\
\text { manufacturing is affected by average } \\
\text { volume of fixed capital in } \\
\text { manufacturing, average amount of labor } \\
\text { in manufacturing, and the growth in } \\
\text { national income produced in } \\
\text { manufacturing with a one-year lag. }\end{array}$ & $\begin{array}{ll}\text { - } & \text { National income } \\
\text { produced in } \\
\text { manufacturing } \\
\text { - } \\
\text { Average volume of fixed } \\
\text { capital in manufacturing } \\
\text { - } \quad \text { Average amount of labor } \\
\text { in manufacturing } \\
\text { Growth in national } \\
\text { income produced in } \\
\text { manufacturing with one- } \\
\text { year lag }\end{array}$ \\
\hline $\begin{array}{l}\text { Bensidoun et } \\
\text { al. [23] }\end{array}$ & $\begin{array}{l}\text { Countries with increasing share in } \\
\text { international trade grew faster. } \\
\text { Used regression analysis to analyze } \\
\text { growth in China. } \\
\text { A positive correlation between the } \\
\text { growth of GDP and of manufacturing. }\end{array}$ & $\begin{array}{ll}- & \text { Growth of export } \\
- & \text { Growth of GDP } \\
- & \text { Growth of GDP } \\
\text { prowth rate of labor } \\
\text { productivity in }\end{array}$ \\
\hline Jeon [24] & $\begin{array}{l}\text { The faster the growth of manufacturing } \\
\text { output, the faster the growth of GDP. } \\
\text { Secondary industry has played a key } \\
\text { role in the overall growth of GDP of the } \\
\text { Chinese economy. }\end{array}$ & $\begin{array}{l}\text { manufacturing } \\
\text { Growth of labor } \\
\text { employment in } \\
\text { manufacturing }\end{array}$ \\
\hline Xing [26] & $\begin{array}{l}\text { Used regression for econometric } \\
\text { analysis. } \\
\text { An appreciation of RMB leads to a } \\
\text { reduction in FDI inflows. }\end{array}$ & $\begin{array}{ll}- & \text { Exchange rate } \\
- & \text { Growth of FDI }\end{array}$ \\
\hline $\begin{array}{l}\text { Christopoulos } \\
\text { [27] }\end{array}$ & $\begin{array}{l}\text { Studied the impact of openness, terms } \\
\text { of trade, human capital and inflation on } \\
\text { efficiency performance. } \\
\text { The model involved econometric } \\
\text { analysis and indexing approach. } \\
\text { Trade openness increases the efficiency } \\
\text { performance of a country. }\end{array}$ & $\begin{array}{ll}- & \text { Openness (ratio of } \\
& \text { exports to GDP) } \\
- & \text { Terms of trade } \\
- & \text { Inflation rate }\end{array}$ \\
\hline Hua [28] & $\begin{array}{l}\text { Built an econometric model by } \\
\text { regression analysis. } \\
\text { Identified a negative effect of the real } \\
\text { appreciation of the RMB on } \\
\text { manufacturing employment. }\end{array}$ & $\begin{array}{l}\text { - } \quad \text { Exchange rate } \\
\text { Growth of employment } \\
\text { in manufacturing }\end{array}$ \\
\hline
\end{tabular}

Swift RMB appreciation: In this overheating economy in China, it is noticeable that RMB appreciation has recently accelerated strongly. Indeed, RMB appreciation is a response to rising pressure from the USA, which could culminate in extensive measures to restrict Chinese exports to the USA. According to statistics $[5,6]$, the appreciation against the US dollar is generally expected to continue at around $4.3-5 \%$ in 2007 and 2008, respectively, and will slow the pace of RMB appreciation at around 4\% in subsequent years.
Suffering from the overheating economy, China's government has been taking steps to cool it down; however, the GDP growth and inflation rate remain high while RMB appreciation seems to be uncontrollable. These problems are even anticipated to continue beyond the year 2008 through the following years, as firms around the region are probably restraining investment in China, injuring its business, manufacturing, and trade prospects. Since foreign direct investment (FDI) accounts for a large proportion of investment in the manufacturing industry, manufacturing prospects will probably be hit hard by the
Fig. 2 The dependent and independent variables in model I

\begin{tabular}{cl}
\hline Dependent Variables & \multicolumn{1}{c}{ Independent Variables } \\
\hline & Total Wages Growth Rate of Staff and Workers (T_WAGE), Total \\
Investment Growth Rate in & Wages Growth Rate in Manufacturing Industry (MANU_WAGE), \\
$\begin{array}{c}\text { Manufacturing Industry } \\
\text { (MANU_INV) }\end{array}$ & $\begin{array}{l}\text { Growth of Consumer Price Index (CPI), Growth of Purchasing Price } \\
\text { Indices of Raw Material, Fuel and Power (PPI), Growth of RMB } \\
\end{array}$ \\
& Exchange Rate to 1 USD (EX_RATE), Constant (C) \\
\hline
\end{tabular}



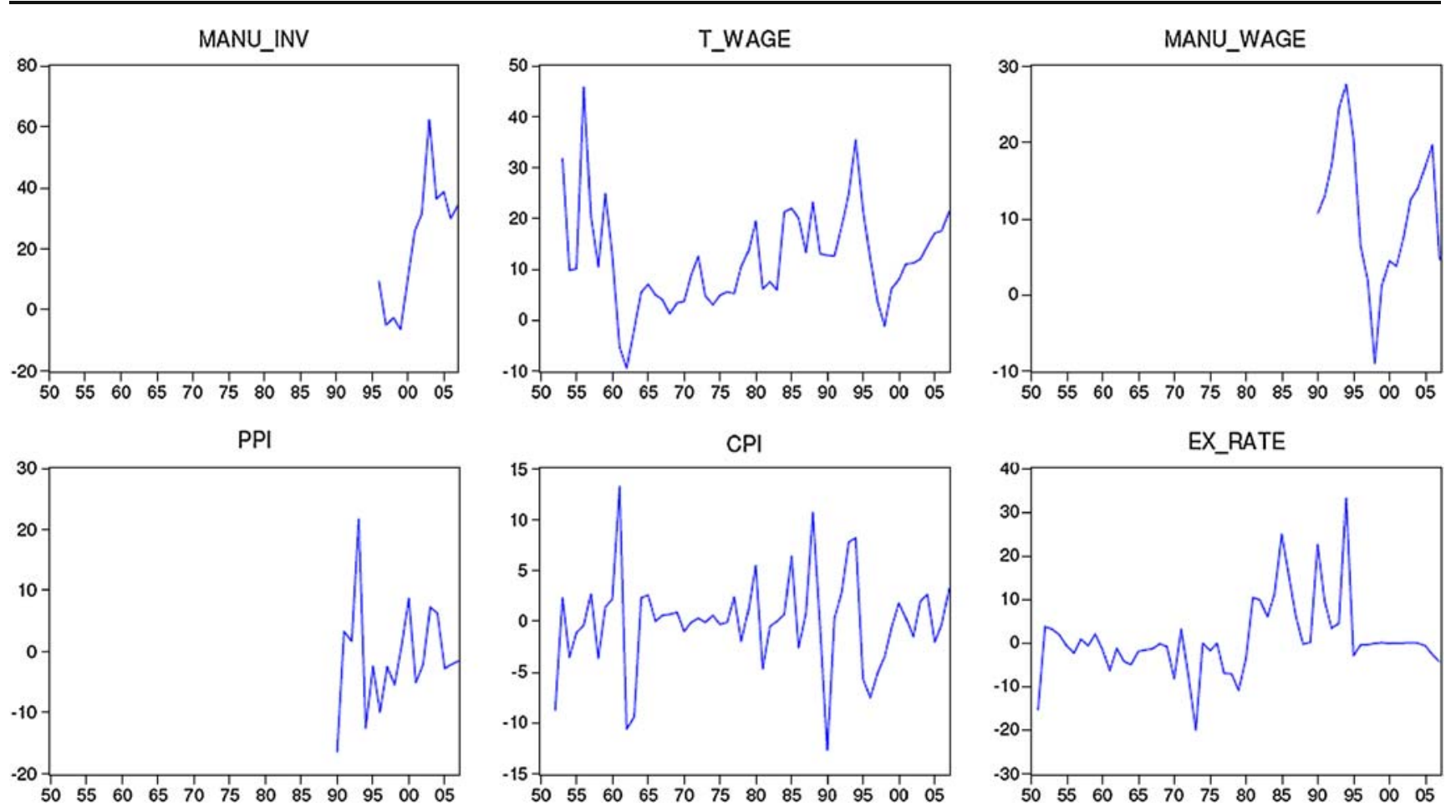

Fig. 3 Multiple graphs of the dataset in model I

overheating economy. Regarding this recent problem, this study is thus designed to address the following two key research questions:

1. Does the overheating economy affect the Chinese manufacturing industry? If so, how?

2. How do the important factors examined in research question 1 tend to be in the subsequent 5 years?

Apart from the above section examining the symptoms of the overheating economy and describing the objectives of this paper, the next section will provide evidence of the links between China's economic factors (including that of the overheating economy) and its industrial activities. Section 3 will mainly review and discuss the economic and manufacturing determinants/variables for the econometric models in the existing literature. The methodology and dataset used in this study will be described in Section 4. The core empirical study, including the model estimation and projection as well as their relevant results and analysis, will be presented in Sections 5 and 6. The last section will summarize the findings and limitation of this study, as well as point out the direction for future research.

\section{Links between economic factors and manufacturing activities}

In the previous section, the statistics clearly indicate that the overheating economy is likely to continue in the coming years. The impacts of this unhealthy economy could not therefore be overlooked, especially on the manufacturing growth. This is because economic growth, trade growth, and FDI in China are closely correlated, forming direct relationships with the manufacturing activities. As emphasized by Joseph [7], understanding the macro environment in terms of industrial background is essential and fundamental previous to formulating an appropriate manufacturing strategy. However, the existing literature on this economic relationship is limited. In this study, the links between economic factors and manufacturing activities are elaborated and analyzed with the statistics and our proposed model.

Due to China's surprisingly robust expansion, many international investors adjusted their expectations upward for China's growth. For instance, the National Bureau of Statistics raised its estimate of China's 2006 growth rate
Fig. 4 The lead and lagged variables in model I

\begin{tabular}{cc}
\hline Lead Independent Variables & Lagged Independent Variables \\
\hline T_WAGE(1), MANU_WAGE(1), CPI(1), PPI(1), & T_WAGE(-1), MANU_WAGE(-1), CPI(-1), \\
EX_RATE(1), C(1) & PPI(-1), EX_RATE(-1), C(-1) \\
\hline
\end{tabular}


Fig. 5 The statistical output of the regression model in model I

\begin{tabular}{lrcrr}
\hline Independent Variable & Coefficient & Std. Error & t-Statistic & Prob. \\
\hline MANU_WAGE(-1) & 2.4724 & 0.7080 & 3.4919 & 0.0101 \\
CPI(1) & 7.0664 & 1.7684 & 3.9959 & 0.0052 \\
T_WAGE & 1.3281 & 0.4903 & 2.7085 & 0.0303 \\
EX_RATE & 22.1817 & 4.1273 & 5.3744 & 0.0010 \\
\hline R-squared & 0.9054 & Mean dependent var. & & 20.9335 \\
Adjusted R-squared & 0.8648 & S.D. dependent var. & & 21.6445 \\
S.E. of regression & 7.9578 & Akaike info criterion & & 7.2615 \\
Sum squared resid. & 443.2905 & Schwarz criterion & & 7.4062 \\
Log likelihood & -35.9381 & Hannan-Quinn criter. & & 7.1703 \\
Durbin-Watson stat & 2.7447 & & & \\
\hline
\end{tabular}

from $10.7 \%$ to $11.1 \%$ [8]. Meanwhile, the National Bureau of Statistics also revised its estimate of total output by $\$ 18.8$ billion to $\$ 2.705$ trillion for 2006 [8]. In the year to the second quarter in 2007, economic and industrial activities in China remained buoyant, with an incredible growth rate reaching $11.9 \%$ [4]. This implies that the growth of China's economy and industrial activities are in fact linked.

Besides, supported by the trade liberalization and investment policy reforms in the developing countries, foreign-invested firms were encouraged to invest in China. In 2005, China was the leading recipient of FDI in the world, receiving almost $\$ 80$ billion [6]. Importantly, China's emphasis on guiding FDI into the manufacturing sector has made China the "world factory". According to the various economic models, China's low wages and its quality of labor are important determinants of FDI in its manufacturing and trade development [9, 10]. This further confirms that the growth of FDI is associated with China's manufacturing activities. These determinants will also be examined in this empirical study afterwards.

In addition, with the massive inflow of FDI, exports of products manufactured by foreign-invested firms grew from $12.5 \%$ in 1990 to $31.5 \%$ in 1995 and $48 \%$ in 2000 [11]. China's total trade balance even jumped from $\$ 32$ billion in 2004 to $\$ 177.5$ billion in 2006 [6]. This not only makes China the world's third largest trading nation after the US and Germany but also supports China's rise regionally and its integration into the global economy. They explain why China's economy, manufacturing output, and exports generally grew at a similar pace and why China is regarded as a global manufacturing base and even named the "world factory" with economic expansion.

The economic factors, especially suffering from overheating, discussed above certainly influence manufacturingrelated activities, including its growth, investment, output, and exports. Since this harmful economic situation has been signaled and appears to be likely to continue in subsequent years, it is valuable for manufacturing firms and investors to identify and get insights into the impacts on the manufacturing industry for improving their business and manufacturing strategy.

\section{Econometric models for manufacturing strategy}

A suitable model can reflect the manufacturing strategy under consideration and provide the prediction of manufacturing capabilities so as to support judgment in the strategy evaluation process [12]. In order to better understand the links between the economic factors we hypothesized earlier, econometric models are thus used for investigation. Econometrics commonly takes account of applying economic theory, mathematics, and statistical techniques for testing hypotheses, estimating coefficients of economic relationships, and forecasting economic phenomena [13]. Econometrics is often recognized as regression analysis; time series methods, however, are supplementary in econometric models. In the present literature, many researchers have studied the performance of econometric against time series models [14-17] and compared that of various time series models [18-21].

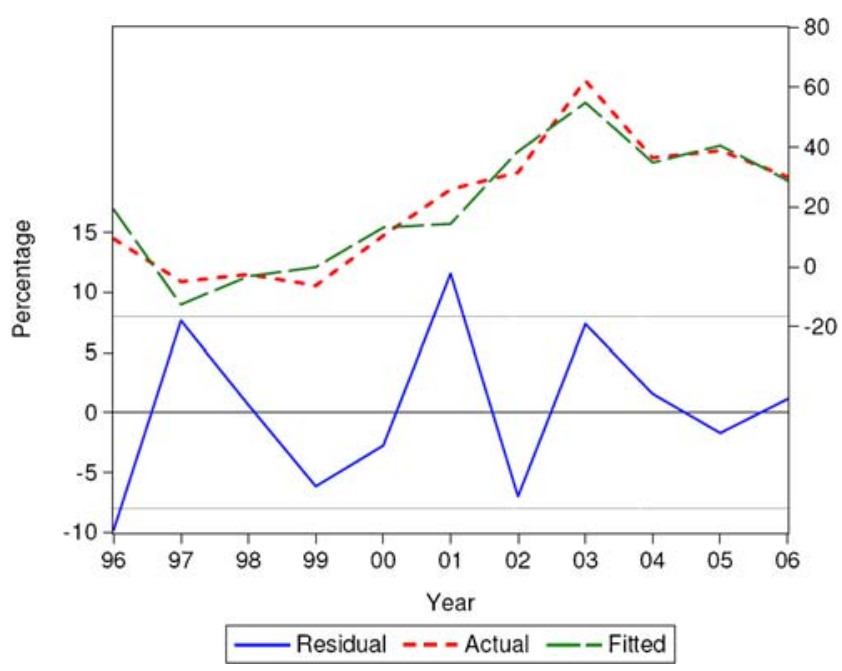

Fig. 6 The actual, fitted, residual graph of the regression model in model I 
Fig. 7 The result of ANOVA

$F$ test in model I

\begin{tabular}{lrrr}
\hline Test for Equality & & & \\
\hline Method & df & Value & Probability \\
\hline Anova F-test & $(4,50)$ & 7.399656 & 0.0001 \\
& & & \\
\hline Analysis of Variance & & & Mean Sq. \\
\hline Source of Variation & df & Sum of Sq. & 854.1848 \\
\hline Between & 4 & 3416.739 & 115.4357 \\
Within & 50 & 5771.787 & 170.1579 \\
Total & 54 & 9188.526 & \\
\hline
\end{tabular}

Indeed, the selection of the econometric method depends on the particular purpose, variables, and data used in the model. Regression analysis is commonly used for studying the causal relationship between variables, while the time series method is favorable in forecasting the time series data. In addition, the simplest time series method, exponential smoothing, often performs as well as complex time series methods, such as Box-Jenkins autoregressive integrated moving average (ARIMA) for the time series with a trend. Hence, the exponential smoothing method, rather than ARIMA, is preferable to be applied for the time series with an obvious trend in this study. On the other hand, as discussed by Ip et al. [22], the ARIMA model can provide knowledge as well as insights into the behaviors of elements considered for better decisions. The ARIMA model is therefore applied in this study as well.

Concerning the determinants of manufacturing strategy, regression analysis is frequently used for investigating the correlation of variables. With reference to some empirical studies, the growth of GDP, trade, and manufacturing are positively related to each other: Higher economic activity at the global level causes acceleration in the expansion of world trade as well as an increase in manufacturing outputs $[23,24]$. This greatly supports the assertion in Sections 1 and 2 that the symptoms of overheating and other economic factors in China impact China's manufacturing growth to some extent. Other literature on econometric models for the Chinese economy and manufacturing are also reviewed and summarized in Fig. 1. Accordingly, the growth of exports, employment rate, GDP growth, exchange rate, inflation rate, etc. are taken into account as the determinants or variables for the construction of econometric models in examining the links between manufacturing and economic factors.

However, these models are incapable of fully investigating how the recent symptoms of the overheating economy in China influence the manufacturing industry. This is because (a) the data used in these models are not recent, mostly excluding the data from 2006 to 2007, and (b) the variables examined in most models are limited, usually including one dependent and one independent variable only, thus failing to investigate the interrelationship between variables. As there are clear signals that the Chinese economy is suffering from overheating and this is raising much concern, this latest study is essential to enable firms with manufacturing activities, and even foreign investors, to gain insights into this problem and thus formulate a more appropriate manufacturing strategy.

\section{Methodology and data source}

Our empirical study makes use of the Chinese historical data from 1950 to 2007 for the development of econometric models. These data related to the Chinese economy and manufacturing industry are collected from the China Statistical Databases. The databases include China's statistical yearbooks, national statistics, etc. provided with the collaboration of the University of Michigan and the All China Marketing Research Co., Ltd. under the authorization of the National Bureau of Statistics of China.

Regarding research question 1, regression analysis is employed to investigate and verify the relationship between the Chinese economic and overheating factors and its manufacturing development, as the regression model is preferred for studying the causal links between variables. On the other hand, time series methods, including exponential smoothing and ARIMA, are used to forecast the variables examined in the regression models to answer research question 2. The variables used and procedures of the model estimation and predication in each model will be discussed individually in Sections 5 and 6. Furthermore, for all econometric models developed in this study, the significance level is specified at $5 \%$.

Fig. 8 The result of model II

\begin{tabular}{ccccccc}
\hline Models & $\alpha$ & $\beta$ & RMSE & SSE/SSR & Mean & Trend \\
\hline II & 0.95 & 1 & 1244.225 & 20125255 & 35347.5 & 8977.4 \\
\hline
\end{tabular}




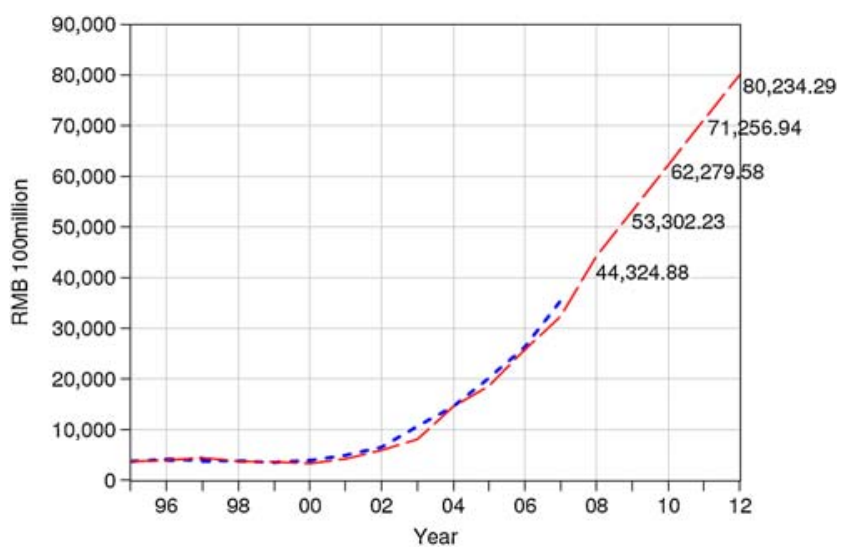

Fig. 9 The actual and forecast series in model II

\section{Model development using regression analysis}

In this empirical study, the least squares method with white heteroskedasticity (i.e., with consistent coefficient covariance) is used to estimate the regression equation, while the combinatorial selection method is applied to select appropriate regressors. In order to determine the best-fit model, the following three steps have to be carried out:

Step 1: $t$ test for the significance of parameters. Since the combinatorial selection method does not consider the $p$ values of the $t$ test, a $t$ test for checking the significance of parameters for the regression model is necessary.

Step 2: statistical measures for the evaluation of model accuracy. With various regression models through different combinations of significant parameters, the statistical measures, including $R^{2}$, SE, Akaike information criterion (AIC), etc. are applied for judging the model accuracy. Meanwhile, the Durbin-Watson (DW) statistic is necessary for testing the auto-correlation within the errors.

Step 3: analysis of variance (ANOVA) for the overall regression significance. ANOVA is used to test the overall significance of the regression model estimated through the null hypothesis that all the coefficients of all independent variables in the regression model are jointly equal to 0 .

5.1 Model I: relationship between the growth of manufacturing industry and overheating symptoms

\subsubsection{Objective and dataset}

Recently, the overheating economy in China has drawn our attention to the impacts of RMB appreciation, inflation, and increasing labor and material costs on the manufacturing industry. These economic factors may influence the production costs, market demand, investment, etc. Therefore, this model is designed to examine the relationship between these factors related to the Chinese overheating economy and the investment in the manufacturing industry so as to investigate whether the flow of investment in the manufacturing industry would be affected by these factors.

The dependent and independent variables used for this model are shown in Fig. 2. The dataset of different variables, showing annual percentage changes, are graphically exhibited in Fig. 3.

\subsubsection{Model estimation results and analysis}

In this model, the lead-lag relationship will be taken into account so as to reinforce the significance of the best-fit regression model. For this reason, the independent variables mentioned above with lead=1 and lag=1 will also be considered in this model. It is noted that the lagged variables are denoted by $(-1)$, while the lead variables are represented by (1). The lead and lagged variables are exhibited in Fig. 4.

The best-fit model is determined through the judgment on model accuracy and the test of DW statistic. The estimation output of the best-fit regression model is shown in Fig. 5. According to the DW statistic test, the model estimated has no correlation among the errors, as its DW statistic value equals 2.7447 , which is close to 2 . Furthermore, the $R^{2}(0.9054)$ and adjusted $R^{2}(0.8648)$ are noticeably equal to 1 , which indicates that the model estimated is a nearly perfect fit. This model estimated also has lower values in SE (7.9578), sum squared errors/ residuals (SSE/SSR, 443.2905), and AIC (7.2615), and a

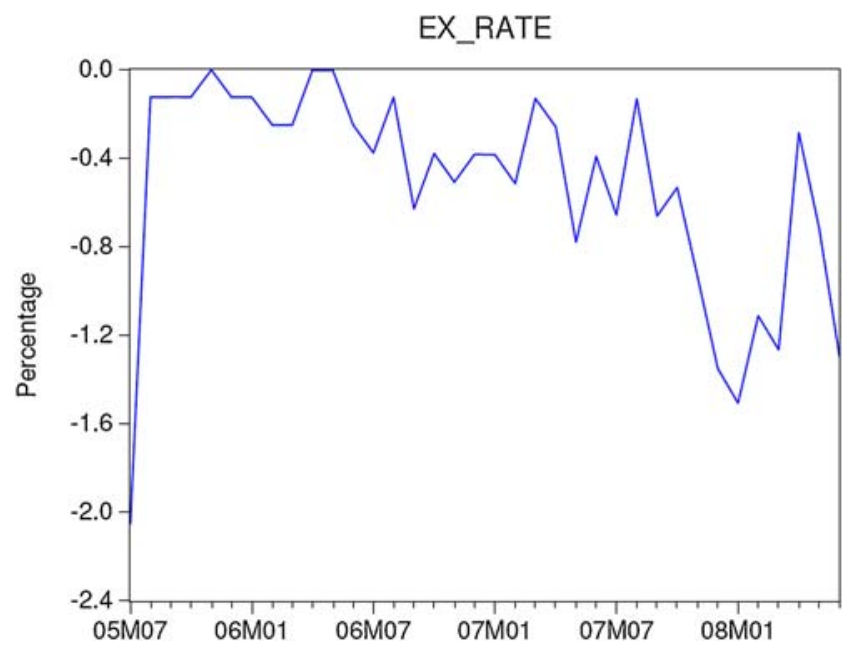

Fig. 10 A graphical representation of EX_RATE in model III 
Fig. 11 The result of ADF test on EX_RATE in model III

\begin{tabular}{|c|c|c|c|}
\hline \multicolumn{4}{|c|}{ Null Hypothesis: EX_RATE has a unit root } \\
\hline & & t-Statistic & Prob. \\
\hline \multicolumn{2}{|c|}{ Augmented Dickey-Fuller test statistic: } & -4.4498 & 0.0012 \\
\hline \multirow[t]{3}{*}{ Test critical values: } & $1 \%$ level & -3.6329 & \\
\hline & $5 \%$ level & -2.9484 & \\
\hline & $10 \%$ level & -2.6129 & \\
\hline
\end{tabular}

higher value in SC (7.4062). Furthermore, the difference between the values of $R^{2}$ and adjusted $R^{2}$ is minor so that the results of the estimated regression model are not negatively influenced by the added regressors.

The following multiple regression represents the best-fit model for the investment growth rate in the manufacturing industry.

$$
\begin{aligned}
\text { MANU_INV = } & 2.4724 \times \text { MANU_WAGE }(-1) \\
& +7.0664 \times \mathrm{CPI}(1)+1.3281 \times \text { T_WAGE } \\
& +22.1817 \times \text { EX_RATE. }
\end{aligned}
$$

According to this multiple regression estimate, all of the coefficients are positive, including the variables of MANU_WAGE $(-1)(+2.4724), \operatorname{CPI}(-1)(+7.0664)$, T_WAGE $(+1.3281)$, and EX_RATE $(+22.1817)$, which indicates that they are positively related to the investment growth in the manufacturing industry in China. A previous study indicates that an appreciation of RMB will lead to a reduction in FDI inflows [27]. Alternatively, it is further found in this study that the appreciation of RMB will result in a reduction in the investment in manufacturing, partic- ularly in which FDI contributes a large proportion to investment in the manufacturing industry. According to the multiple regression estimated, the EX_RATE is in fact more important in explaining the variation of the MANU INV due to its relatively large coefficient value. It is noted that the positive coefficient of the lagged variable, MANU WAGE $(-1)(+2.4724)$ shows evidence that the investment growth in the manufacturing industry tends to lead the wages in that industry. Alternatively, the positive coefficient of the lead variable, CPI $(-1)(+7.0664)$, indicates that the consumer price index has a tendency to lead the investment growth in the manufacturing industry.

The graph for the actual, fitted, and residual estimates of the regression model is exhibited in Fig. 6. The residual line shown in Fig. 6 has a random pattern which indicates that the errors of the projected values in the regression model are unrelated. The actual and fitted lines refer to the actual and projected values of the investment growth rate in the manufacturing industry, respectively. Importantly, the actual and fitted lines have almost the same pattern, indicating that the growth rate of investment in the manufacturing industry is significantly interrelated with wages in the industry with
Fig. 12 The estimation output of the ARIMA $(0,0,6)$ in model III

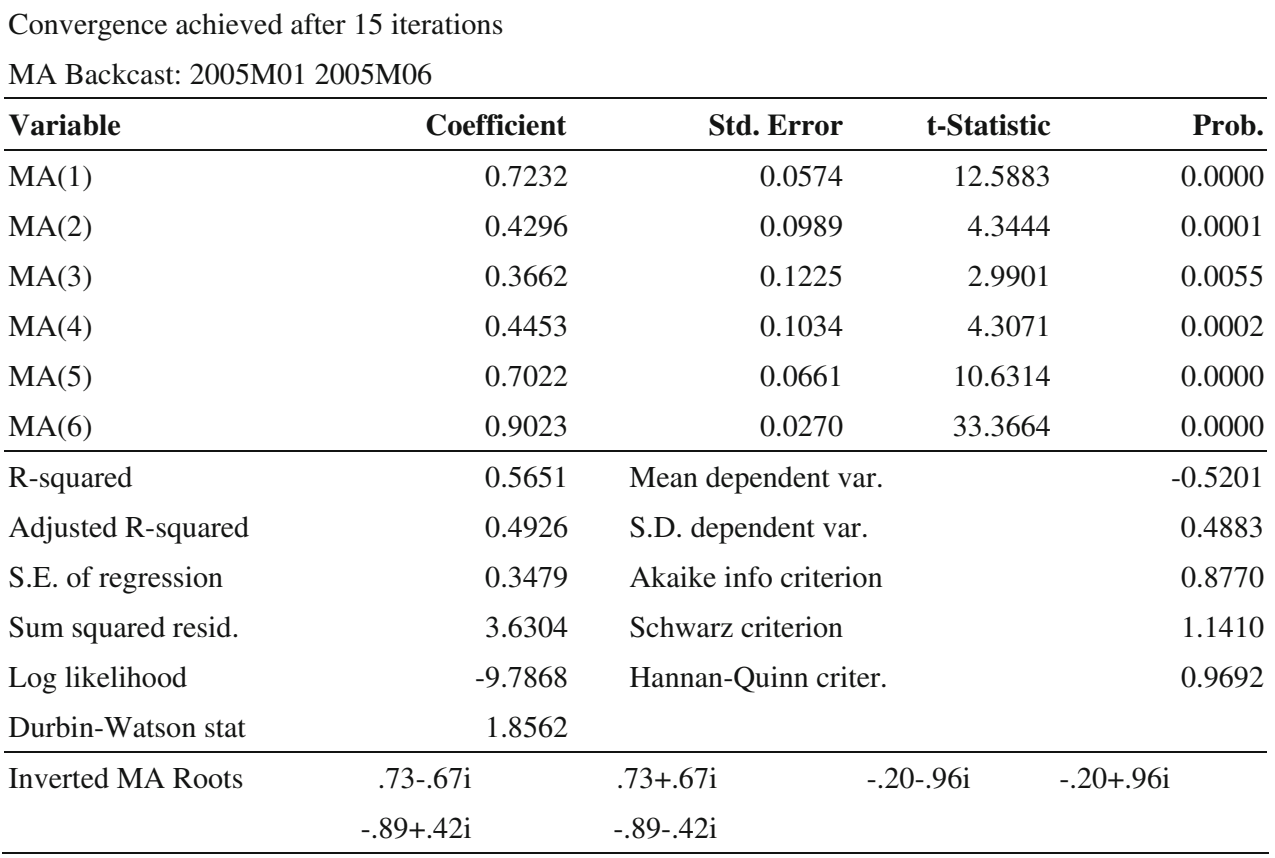




\begin{tabular}{|c|c|c|c|c|c|}
\hline Autocorrelation & Partial Correlation & $A C$ & PAC & Q-Stat & Prob \\
\hline 1 & 1 d & $1-0.092$ & -0.092 & 0.3336 & \\
\hline I & $1]$ & 20.012 & 0.004 & 0.3396 & \\
\hline 10 & 10 & $3-0.110$ & -0.110 & 0.8453 & \\
\hline 1 百 & 1 日 & $4-0.135$ & -0.159 & 1.6281 & \\
\hline 1 & 10 & $5-0.052$ & -0.084 & 1.7468 & \\
\hline 101 & 111 & $\begin{array}{ll}6 & 0.051\end{array}$ & 0.024 & 1.8661 & \\
\hline $1 \theta_{1}$ & ！口। & $\begin{array}{ll}7 & 0.229\end{array}$ & 0.213 & 4.3320 & 0.037 \\
\hline 101 & 101 & 80.084 & 0.110 & 4.6753 & 0.097 \\
\hline 101 & 1 \& 1 & $\begin{array}{cc}9 & -0.081\end{array}$ & -0.075 & 5.0092 & 0.171 \\
\hline 17 & 11 & $10-0.007$ & 0.026 & 5.0117 & 0.286 \\
\hline 10 & 10 & $11-0.146$ & -0.065 & 6.1763 & 0.289 \\
\hline 17 & 1 & $12-0.055$ & -0.052 & 6.3466 & 0.386 \\
\hline ， 口1 & 101 & $\begin{array}{ll}13 & 0.117\end{array}$ & 0.087 & 7.1562 & 0.413 \\
\hline 151 & $1 \sqrt{1}$ & $14 \quad 0.023$ & -0.038 & 7.1885 & 0.516 \\
\hline b 1 & 11 & $\begin{array}{ll}15 & 0.069\end{array}$ & -0.003 & 7.4943 & 0.586 \\
\hline 1. 1 & 101 & $16 \quad 0.043$ & 0.080 & 7.6211 & 0.666 \\
\hline
\end{tabular}

Fig. 13 The correlogram of the residuals of ARIMA $(0,0,6)$ in model III

lag $=1$, consumer price index with lead $=1$, total wages of staff and workers, and exchange rate.

\subsubsection{Results of hypothesis tests}

In order to support the estimated regression model above, two hypothesis tests were conducted. The results are as follows:

The hypotheses of the $t$ test to be tested in this model are:

$H_{0}: C_{i}=0$ versus $H_{1}: C_{i} \neq 0$,

where $C$ refers to the coefficients of variables, including all the lead and lagged variables, and constant terms in the regression model, and $i=1,2,3, \ldots, 18$. The variables MANU_WAGE(-1), CPI(1), T_WAGE, and EX_RATE are proven to be statistically significant, as their $p<0.05$ under the $t$ test. This rejects the null hypothesis of zero coefficients of the variables.

The hypotheses of ANOVA to be tested in this model are:

$H_{0}: C_{1}=C_{2}=C_{3}=C_{4}=0$ versus $H_{1}:$ not all $C_{i}=0$,

where $i=1,2,3,4$. The result of the ANOVA $F$ test is demonstrated in Fig. 7. The result of the ANOVA test explicitly indicates that there is a significant relationship between the dependent variable (MANU_INV) and independent variables (MANU_WAGE(-1), CPI(1), T_WAGE, and EX_RATE). This is because the $p$ value of the ANOVA $F$ test equals 0.0001 , which is smaller than 0.05 ; the null hypothesis is therefore rejected.

\section{Forecasting using Holt-Winters and ARIMA models}

The time series data, MANU_INV, is likely to show a trend without seasonality; hence, the Holt-Winters no seasonal exponential smoothing method is used for forecasting. Alternatively, the time series data, EX RATE, is quite fluctuated and constant so that ARIMA analysis is used for forecasting.

\subsection{Model II: forecasting models using Holt-Winters}

\subsubsection{Objective and dataset}

As MANU_INV is closely related to the overheating economic factors in China, such as CPI, exchange rate, wages, etc., with reference to the result of the model I discussed above, its forecast would be important to decision makers in the manufacturing industry. Model II is thus designed to forecast the series of MANU_INV (in RMB 100 million) in China using the Holt-Winters exponential smoothing method. The dataset in 1952-2007 will be used.

\subsubsection{Results and analysis of model II}

Through minimizing the root mean squared error and SSE/ SSR, the best-fit model is determined and its result shown in Fig. 8. The smoothing parameters, $\alpha$ and $\beta$, in this model are mostly equal to 1 , indicating that the series of the dataset is a random walk where the most recent value is the best for estimating the future values.

By using the particular smoothing parameters estimated in the model stated in Fig. 8 above, a forecast model is performed. The values for the forecasting period (2008-2012) after the estimation period (1995-2007) for MANU_INV are then projected (see Fig. 9). According to Fig. 9, the growth of investment in the manufacturing industry (MANU_INV) is anticipated to maintain an upward trend in the coming 5 years.

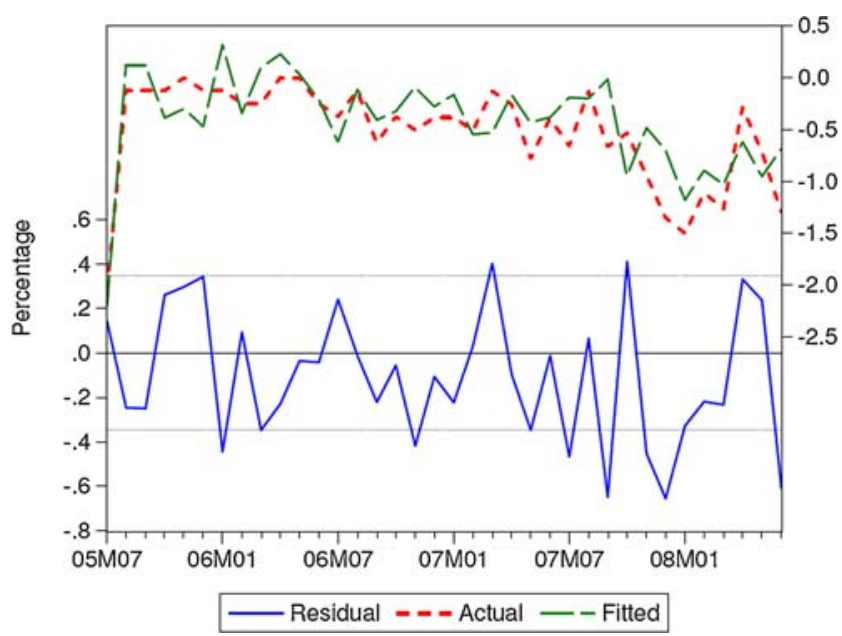

Fig. 14 The actual, fitted, residual graph of the ARIMA $(0,0,6)$ in model III 
Fig. 15 The evaluation output and graph of the model forecast in model III

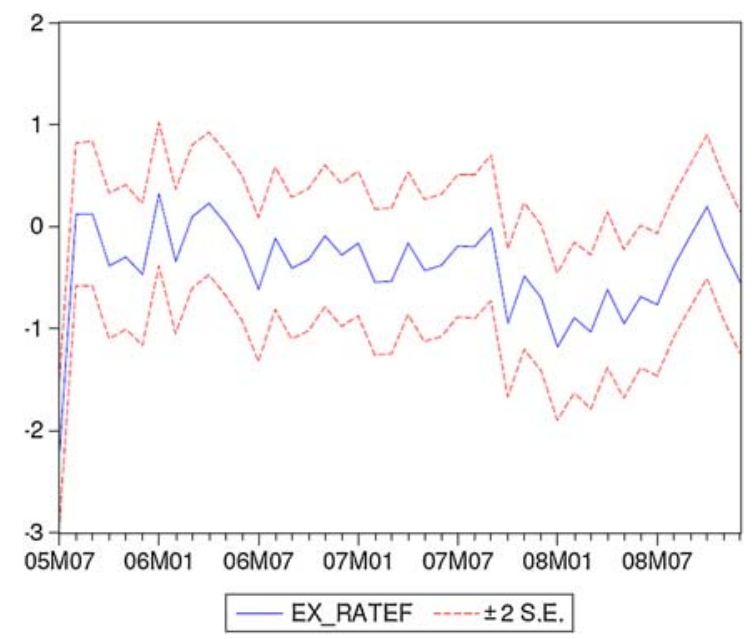

Forecast: EX RATEF

Actual: EX_RATE

Forecast sample: 2005M07 2008M12

Included observations: 36

Root Mean Squared Error

Mean Absolute Error

Mean Abs. Percent Error

Theil Inequality Coefficient

Bias Proportion

Variance Proportion

Covariance Proportion
0.317561

0.265363

77.63411

0.238072

0.110785

0.001792

0.887423
Importantly, this implies that the overheating economy in China will not negatively affect the inflow of manufacturing investment from 2008 to 2012 to a large extent.

\subsection{Model III: forecast RMB exchange rate using ARIMA}

\subsubsection{Objective and dataset}

According to the regression model resulted in model I, the EX_RATE is highly correlated to investment in the manufacturing industry due to its large coefficient. Further, as mentioned earlier, Xing [26] indicates that an appreciation of the RMB will lead to a reduction in FDI inflows. In fact, the appreciation of the RMB has recently drawn attention to the FDI in the manufacturing industry in China. Hence, a model forecasting the RMB exchange rate to 1 USD using ARIMA is designed. As the Chinese authorities have allowed greater flexibility in the RMB since the middle of 2005, the dataset of EX RATE, in percentage change, for the period 2005M07-2008M06 will be used for forecasting the values of the period 2008M07-2008M12 using the static forecast method.

\subsubsection{Results and analysis}

The estimation result of the best-fit ARIMA $(p, d, q)$ model will be discussed based on the following three steps, where $p, d$, and $q$ refer to the AR (autoregression), I (integrated or order of differencing), and MA (moving average) terms of the model.

Step 1: identification of difference(s). The graphical representation of the EX RATE is exhibited in Fig. 10, which demonstrates that the time series data likely appears to be stationary. This shows that the EX RATE series requires no integration order, i.e., the order of differencing. The result of the augmented Dickey-Fuller (ADF) test on EX_RATE also confirms that the order of differencing for the best ARIMA model is equal to 0 , i.e., $d=0$ (see Fig. 11). This is because the null hypothesis that EX_RATE has a unit root is rejected, as the value of the $\overline{A D F} t$ statistic $(-4.4498)$ is smaller than the $t$ statistic critical value $(-2.9484)$ at the $5 \%$ significance level.

Step 2: model estimation and diagnosis. In order to determine the best-fit ARIMA model, various ARIMA models with different combinations of the model components in terms of the degree of $p$ and $q$ are constructed, followed by model judgment through comparing their statistical results. Through the trial and error procedure, the best-fit model is determined as ARIMA $(0,0,6)$ in which the estimation output is shown in Fig. 12. According to Fig. 12, the adjusted $R^{2}$ of the model is 0.4926 , SSR is 3.6304 , and AIC is

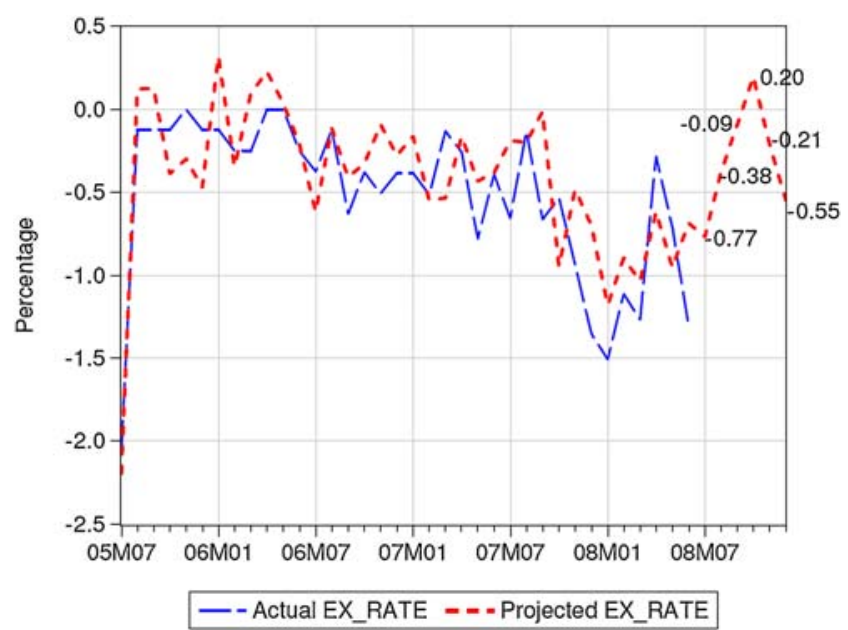

Fig. 16 The actual and projected EX_RATE series in model III 
0.8770. Regarding the residual test, the correlogram of the residuals of ARIMA $(0,0,6)$ is shown in Fig. 13. Since there is no significant pattern in the ACF and PACF, the ARIMA $(0,0,6)$ model selected as the best model contains white noise. Figure 14 shows a single graph with actual, fitted, and residual lines of the ARIMA $(0,0,6)$ model for illustration.

Furthermore, the ARIMA $(0,0,6)$ model can be expressed as the following equations:

$$
\begin{aligned}
Y_{\mathrm{t}}= & \left(1-\theta_{1} B-\theta_{2} B^{2}-\theta_{3} B^{3}-\theta_{4} B^{4}-\theta_{5} B^{5}-\theta_{6} B^{6}\right) \varepsilon_{t} \\
Y_{\mathrm{t}}= & \left(\begin{array}{l}
1-0.7232 B-0.4296 B^{2}-0.3662 B^{3}-0.4453 B^{4} \\
-0.7022 B^{5}-0.9023 B^{6}
\end{array}\right) \varepsilon_{t} \\
Y_{\mathrm{t}}= & \varepsilon_{t}-\theta_{1} \varepsilon_{t-1}-\theta_{2} \varepsilon_{t-2}-\theta_{3} \varepsilon_{t-3}-\theta_{4} \varepsilon_{t-4}-\theta_{5} \varepsilon_{t-5}-\theta_{6} \varepsilon_{t-6} \\
Y_{\mathrm{t}}= & \varepsilon_{t}-0.7232 \varepsilon_{t-1}-0.4296 \varepsilon_{t-2}-0.3662 \varepsilon_{t-3}-0.4453 \varepsilon_{t-4} \\
& \quad-0.7022 \varepsilon_{t-5}-0.9023 \varepsilon_{t-6}
\end{aligned}
$$

where $Y_{\mathrm{t}}$ is the output series, $B$ is the backshift operator, $\varepsilon_{t}$ is the random noise, and $\theta$ is the polynomial.

Step 3: model forecast. Through the equation of the $\operatorname{ARIMA}(0,0,6)$ model mentioned above and using the static forecast method, the time series of EX_RATE is forecasted. The evaluation output and graph of the forecast of the EX_RATE is exhibited in Fig. 15. The actual and projected EX_RATE series are plotted in a single graph for illustration (see Fig. 16). The projected values for the growth of the Chinese exchange rate (EX_RATE) during the period 2008M07-2008M12 are also stated in Fig. 16.

Figure 16 reveals that the exchange rate of the RMB will slow down from $-1.29 \%$ in $2008 \mathrm{M} 06$ to $-0.77 \%$ in $2008 \mathrm{M} 07$ as well as in the subsequent months. This means that the appreciation rate of the RMB against the USD will decelerate in the near future, a conclusion that is consistent with the EIU and World Bank forecasts as discussed earlier. Further, the forecast result (i.e., the slowdown of RMB appreciation) provides further evidence to support and explain the result of model II (i.e., the growth of MANU INV would not be hindered significantly but still continue a gradual upward trend).

\section{Conclusion}

This paper first discusses the links between economic and industrial activities, then empirically studies the impacts of the overheating economic factors on the manufacturing industry, and finally projects their trends in the coming 5 years. Through this empirical study, the following vital conclusions can be drawn. (a) The symptoms of the overheating economy, except RMB appreciation, have a positive relationship with the inflow of investment in the manufacturing industry. This study provides further evidence that RMB appreciation may not only result in a reduction in the FDI inflows mentioned by Xing [26] but also lead to a decline in the growth of investment in the manufacturing industry in China.

(b) In the coming 5 years, the growth of the investment in manufacturing will be gradual, as RMB appreciation is predicted to slow down.

There is perhaps a limitation that relates to the estimated ARIMA model, which has a moderate rather than a strong statistical output. However, it is still acceptable and even more accurate to trace the fluctuated time series of the RMB exchange rate than to use other time series methods, such as exponential smoothing. Future research could be conducted to validate these determinants and their impacts on different sizes of manufacturing enterprises and even in various manufacturing sectors. The incorporation of these determinants into the manufacturing strategy formulation process could then be further researched.

Acknowledgment The authors would like to express their sincere thanks to the Hong Kong Polytechnic University for its financial support for this research work under Teaching Company Scheme project number ZW98.

Open Access This article is distributed under the terms of the Creative Commons Attribution Noncommercial License which permits any noncommercial use, distribution, and reproduction in any medium, provided the original author(s) and source are credited.

\section{References}

1. Economist Intelligence Unit (EIU) (2007a) Asia and Australasia: regional overview. Country forecast. The Economist Intelligence Unit Limited, UK (July)

2. Asian Development Bank (ADB) (2007) Asian development outlook 2007 update. Asian Development Bank, Philippines

3. The Economist Newspaper Limited (2007a). Is inflation China's latest export? The Economist print edition, China's Economy, August 2

4. The Economist Newspaper Limited (2007b) China's booming economy is helping to support global growth as America turns sickly. The Economist print edition, China's Economy, September 27

5. Economist Intelligence Unit (EIU) (2007b) Global outlook. Country forecast. The Economist Intelligence Unit Limited, UK, (September)

6. The World Bank (2007) World Development Indicators online database

7. Joseph AT (1999) Formulation of manufacturing strategy. Int J Adv Manuf Technol 15:522-535 doi:10.1007/s001700050098

8. China Daily (2007) China to be third largest economy. China Daily News, July 11 
9. Fung KC, Lizaka H, Parker S (2002a) Determinants of U.S. and Japanese direct investment in China. J Comp Econ 30:567-578 doi:10.1006/jcec.2002.1788

10. Fung KC, Lizaka H, Lin C, Siu A (2002b) An econometric estimation of locational choices of foreign direct investment: the case of Hong Kong and U.S. firms in China. University of California and University of Hong Kong, mimeo

11. Wei Y, Liu X (2001) Foreign direct investment in China: determinants and impact. Edward Elgar, Cheltenham

12. Baines TS, Harrison DK, Kay JM, Hamblin DJ (1998) A consideration of modeling techniques that can be used to evaluate manufacturing strategies. Int J Adv Manuf Technol 14:369-375 doi:10.1007/BF01178917

13. Salvatore D, Reagle D (2001) Schaum's outline of - theory and problems of statistics and econometrics, , 2nd edn. McGraw-Hill, New York

14. Box GEP, Tiao GC (1975) Intervention analysis with applications to economic and environmental problems. J Am Stat Assoc 70:7C79

15. Makridakis S, Hibon M (1979) Accuracy of forecasting: an empirical investigation. J R Stat Soc [Ser A]:97-145 doi:10.2307/2345077

16. Schmidt J (1979) Forecasting state retail sales: econometric vs time series models. Ann Reg Sci 8:Y1-101

17. Zobcr M (1981) A comparison of Box-Jenkins methods of forecasting with regression. First International Symposium on Forecasting, Quebec, Canada

18. Newbold P, Granges CWJ (1974) Experience with forecasting univariate time series and the combination of forecasts. J R Stat Soc [Ser A](137):131-165 doi:10.2307/2344546

19. Geurts MD, Ibrahim IB (1975) Comparing the Box-Jenkins approach with the exponentially smoothed forecasting model application to Hawaii tourists. J Mark Res 12:182-188 doi:10.2307/3150441

20. Hollier RH, Khir M, Storey RR (1981) A comparison of shortterm adaptive forecasting methods. OMEGA Int J Manag Sci 9:96-98

21. Poulos L, Kvanli A, Pavur R (1987) A comparison of the accuracy of the Box-Jenkins method with that of automated forecasting methods. Int J Forecast 3:X1-267 doi:10.1016/01692070(87)90007-0

22. Ip WH, Fung R, Keung KW (1999) An investigation of stochastic analysis of flexible manufacturing systems simulation. Int J Adv Manuf Technol 15:244-250 doi:10.1007/s001700050063

23. Bensidoun I, Gaulier G, Unal-Kesenci D (2002) The nature of specialization matters for growth: an empirical investigation. CEPII 13 (December)

24. Jeon YB (2006) Manufacturing, increasing returns and economic development in China, 1979-2004: a Kaldorian approach. University of Utah, Working Paper no. 2006-08

25. Yu QL (1990) An econometric model of China's national income. Econ Model, pp 258-262 (July). doi:10.1016/0264-9993(90) 90011-R

26. Xing YQ (2006) Why is China so attractive for FDI? The role of exchange rates. China Econ Rev 17:198-209 doi:10.1016/j. chieco.2005.10.001

27. Christopoulos DK (2007) Explaining country's efficiency performance. Econ Model 24:224-235 doi:10.1016/j. econmod.2006.07.002

28. Hua P (2007) Real exchange rate and manufacturing employment in China. China Econ Rev 18:335-353 doi:10.1016/j.chieco.2007.02.001 